\title{
UPAYA PENGENDALIAN KOMPLIKASI DIABETES MELITUS DI RT 08 KELURAHAN 22 ILIR PALEMBANG
}

\author{
Yofa Anggriani Utama ${ }^{*}$ \\ STIK Bina Husada Palembang \\ email : yofaanggriani@yahoo.co.id \\ Sutrisari Sabrina Nainggolan ${ }^{2}$ \\ STIK Bina Husada Palembang \\ email : sutrisarisabrinanainggolan@gmail.com
}

\begin{abstract}
ABSTRAK
Kurangnya pengetahuan masyarakat mengenai diabetes melitus dan cara pengendalian diabetes melitusakanmenyebabkanmemiliki potensi resiko patologis termasuk infeksi, ulserasi dan amputasi. Selainitu, di masa pandemic Covid 19 ini, penyakitdiabetes melitus merupakan salah satu faktor comorbid Covid-19 yang dapat mengakibatkan kematian pada pasien diabetes melitus Adapun tujuan dilaksanakan kegiatan pengabdian masyarakat ini adalah untuk meningkatkan pengetahuan masyarakat tentang komplikasi diabetes mellitus.dan meningkatkan kemampuan penderita dalam pencegahan komplikasi diabetes mellitus dengan melakukan senam kaki diabetikum.Metode pelaksanaan pengabdian ini dengan memberikan edukasi kesehatan secara on line pada pasien Diabetes melitus. Edukasi kesehatan ini dilakukan secara on line menggunakan media google meet. Kegiatan ini diikuti oleh 60 orang peserta Berdasarkan hasil kegiatan didapatkanbahwapengetahuansebelum diberikan edukasi sebanyak 45 orang (75\%) pasien diabetes mellitus memiliki pengetahuan yang kurang baik tentang edukasi diabetes melitus dan senam kaki diabetik. Setelah diberikan edukasi terjadi peningkatan pengetahuan sebanyak 50 orang (83\%) peserta pengabdian masyarakat memiliki pengetahuan baik tentang edukasi diabetes melitus dan senam kaki diabetik.
\end{abstract}

Kata Kunci : diabetes melitus,senam kaki diabetik, pengetahuan

\section{ABSTRACT}

Lack of public knowledge about diabetes mellitus and how to control diabetes mellitus will lead to potential pathological risks including infection, ulceration and amputation. In addition, during the Covid-19 pandemic, diabetes mellitus is one of the comorbid factors for Covid-19 that can lead to death in diabetes mellitus patients. The purpose of this community service activity is to increase public knowledge about complications of diabetes mellitus. and improve the patient's ability to prevent complications of diabetes mellitus by doing diabetic foot exercises. The method of implementing this service is by providing online health education to Diabetes mellitus patients. This health education is carried out online using the Google Meet media. This activity was attended by 60 participants. Based on the results of the activity, it was found that knowledge before being given education was 45 people (75\%) of diabetes mellitus patients had poor knowledge about diabetes mellitus education and diabetic foot exercises. After being given education, there was an increase in knowledge as many as 50 people (83\%) of community service participants had good knowledge about diabetes mellitus education and diabetic foot exercises.

Keywords : diabetes mellitus, diabetic foot exercise, knowledge

* Koresponden 


\section{PENDAHULUAN}

Menurut data International diabetes Federation (IDF) menyatakan bahwa diabetes melitus merupakan masalah kesehatan terbesar secara global, serta dapat mengakibatkan komplikasi, diperkirakan pada tahun 2013 2017 terdapat kenaikan jumlah pasien diabets melitus dari 103 juta menjadi 16,7 juta pada tahun 2045(IDF Diabetes Atlas, 2017). Negara diwilayah Arab-Afrika Utara, dan PasifikBarat menempati peringkat pertama dan ke-2 dengan prevalensi diabtes pada penduduk umur $20-79$ yahun tertinggi diantara 7 regional di dunia yaitu sebesar $12,2 \%$ dan $11,4 \%$. Wilayah asia tenggara dimana indonesia berada menempati peringkat ke 3 dengan prevalensi sebesar $11,3 \%$. IDF juga memproyeksikan jumlah penderita diabetes pada penduduk umur 20sampaiumur79 tahun pada beberapa negara didunia yang telah mengidentifikasi 10 negara dengan jumlah penderita tertinggi. Cina, India dan Amerika serikat menempati urutan ke tiga teratas dengan jumlah penderita 116,4 juta, 77 juta dan 31 juta. Indonesia berada di peringkat ke -7 antara 10 negara dengan jumlah penderita terbanyak yaitusebesar 10,7 juta. Indonesia menjadi satu-satunya negara di Asia Tenggara, sehingga dapat diperkirakan besarnya kontribusi indonesia terhadap prevalensi kasus diabetes melitus (Infodatin Pusat Data dan Informasi Kementerian Kesehatan RI, 2020).

Berdasarkan data prevalensi diabetes melitus di Provinsi Sumatera Selatan menyatakan bahwa data penduduk Sumatera Selatan dengan diabetes melitus disetiap daerah meliputi : Komering ulu 1,76\% penduduk, Ogan Komering Ilir 1,19\% penduduk, Muara Enim $118 \%$ penduduk, Lahat 1,59\% penduduk, Musi Rawas 0,70\% penduduk, Musi Banyuasin 0,31\% penduduk, Ogan Komering Ulu Selatan 1,05\% penduduk, Ogan Komering Ulu Timur 1,21 \% penduduk, Ogan Ilir 0,83\% penduduk, Empat Lawang 0,39 \% penduduk, Penukal Abab Lematang Ilir 0,58 \% penduduk, Musi Rawas Utara 0,93 \% penduduk, Kota Palembang 2,20\% penduduk, Kota Prabumulih $2,02 \%$ penduduk, Kota Pagaralam 1,25\% penduduk, Kota Lubuk Linggau 1,27 \% penduduk (Badan Penelitian dan Pengembangan Kesehatan, 2019).
Penderita diabetes melitus terjadi akibat kekurangan insulin yang menghambat transfer glukosa ke sel-sel dijaringan tubuh yang menyebabkan sel-sel didalam tubuh kekurangan glukosa dalam darah yang menyebabkan kelemahan otot sehingga dapat menggangu keseimbangan dan peningkatan resiko jatuh pada penderita diabetes melitus, dengan dilakukannya senam kaki diabetik dapat memperlancar peredaran darah dikaki dan jaringan perifer(Sutarti et al., 2018).

Kaki diabetik merupakan salah satu komplikasi diabetes melitus yang paling sering terjadikomplikasi yang memiliki potensi resiko patologis termasuk infeksi, ulserasi dan amputasi. Untuk mencegah komplikasi tersebut dapat dilakukan aktivitas fisik dan olahraga berupa latihan aerobik dapat meningkatkan peredaran darah dan nilai ante branchial indeks sehingga dapat mencegah terjadinya komplikasi kaki diabetik pada penderita diabetes melitus (Matos et al., 2018).

Untuk meningkatkan pengetahuan terhadap kadar gula darah terhadap diabetes militus di masyarakat. Kegiatan ini dilakukan dengan metode penyuluhan. Hasil yang didapatkan menunjukan sebagian besar warga (80\%) belum memahami dan mengerti tentang pemeriksaan diabetes mellitus (Lita Puspita, dkk, 2020).

Peningkatan pengetahuan tentang manajemen diet DM secara umum dan manajemen diet bagi penderita DM di masa pandemi Covid-19 dengan memanfaatkan sumberdaya lokal dan pendekatan budaya Minangkabau. Sebelum diberikan edukasi sebagian besar $(80 \%)$ pasien DM memiliki pengetahuan yang kurang baik tentang manajemen diet pasien DM. Setelah diberikan edukasi terjadi peningkatan pengetahuan pasien DM sebesar 85\% sudah memiliki pengetahuan yang baik tentang manajemen diet(Desnita et al., 2020).

Berdasarkan survey pendahuluan di RT 08 Kelurahan 22 Ilir Palembang didapatkan dari 5 orang penderita Diabetes melitus menyatakan bahwa kurangnya pengetahuan masyarakat mengenai diabetes melitus dan cara pengendalian diabetes melitus, hal ini terjadi karena kurangnya informasi yang didapat kan 
masyarakat mengenai Pengendalian komplikasi diabetes melitus, berdasarkan hal tersebut penelitian melaksanakan pengabdian masyarakat di RT 08 Kelurahan 22 Ilir Palembang untuk mencegah terjadinya komplikasi pada pasien Diabetes melitus dimasa pandemik covid 19 saat ini, dimana penyakit diabetes melitus merupakan salah satu faktor comorbid covid 19 yang dapat mengakibatkan kematian pada pasien diabetes melitus.

\section{METODE \\ MASYARAKAT}

Metode pelaksanaan pengabdian ini dengan memberikan edukasi kesehatan secara on line pada pasien Diabetes melitus. Edukasi kesehatan ini dilakukan secara on line menggunakan media google meet. Jumlah peserta sebanyak 60 orang.

Pelaksanaan kegiatan digunakan media leaflet mengenai materi diabetes melitus yang terdiri dari pengertian, penyebab, tanda dan gejala, komplikasi, penatalaksanan dan pengendalian Diabetes melitus, sedang untukpelaksanaansenam kaki diabetikdisampaikanmelalui video senam kaki diabetik. Setelahpesertamelihat video senam kaki diabetik, peserta diminta untuk mendemonstrasikan senam kaki diabetic melalui media google meet.

Evaluasi dilakukan mengunakan kuesioner mengenai upaya pengendalian komplikasi Diabetes melitus, pres test dan post test dilakukan untuk menilai keberhasilan dalam menyampaikan materi kepada pasien Diabetes Melitus setelah diberikan pengetahuan pasien dapat memahami isi materi yang disampaikan dan dapat menerapkannya.

\section{HASIL}

\section{PENGABDIAN}

\section{MASYARAKAT}

Kegiatan pengabdian masyarakat berbasis virtual dilaksanakanberupaedukasi "Upaya PengendalianKomplikasi

Diabetes

Melitus"dilaksanakanpada hari Sabtu, 08 Mei 2021, secara online dengan menggunakan media google meet. Jumlah total peserta sebanyak 60 orang. Edukasi diberikan dalam 2 sesi, sesi pertama yaitu penyampaian materi edukasi tentang diabetes melitus pada pasien diabetes melitus, sedangkan sesi ke 2 penyampaian materi mengenai senam kaki diabetik. Saat pelaksanaan kegiatan ini diakukan sesi diskusi dan tanya jawab mengenai upaya pengendaliankomplikasidiabetes melitus. Adapun hasil dari kegiatan pengabdian kepada masyarakat terdapat peningkatan pengetahuan masyarakat mengenai Upaya PengendalianKomplikasiDiabetes Melitus tergambar pada tabel 1 Sebagai berikut :

Tabel 1 Distribusi Frekuensi Tingkat Pengetahuan Peserta Pengabdian Kepada Masyarakat tentang Edukasi Diabetes Melitus dan Senam Kaki Diabetik

\begin{tabular}{cccccc}
\hline N & Pengetahua & \multicolumn{2}{c}{ Pre test } & \multicolumn{2}{c}{ Postest } \\
\cline { 3 - 6 } o & n & $\mathrm{n}$ & $\%$ & $\mathrm{n}$ & $\%$ \\
\hline 1 & Baik & 1 & 25 & 5 & 83 \\
& & 5 & & 0 & \\
\hline 2 & Kurang Baik & 4 & 75 & 1 & 17 \\
& & 5 & & 0 & \\
\hline & Total & 6 & 10 & 6 & 10 \\
& & 0 & 0 & 0 & 0 \\
\hline
\end{tabular}

Berdasarkan tabel diatas didapatkan bahwa tingkat pengetahuan sebelum diberikan edukasi sebanyak 45 orang (75\%) pasien DM memiliki pengetahuan yang kurang baik tentang edukasi diabetes melitus dan senam kaki diabetik. Setelah diberikan edukasi terjadi peningkatan pengetahuan sebanyak 50 orang $(83 \%)$ peserta pengabdian masyarakat memiliki pengetahuan baik tentang edukasi diabets melitus dan senam kaki diabetik.

Dokumentasi kegiatan pengabdian kepada masyarakat yang dilaksanakan dapat dilihat pada gambar sebagai berikut :

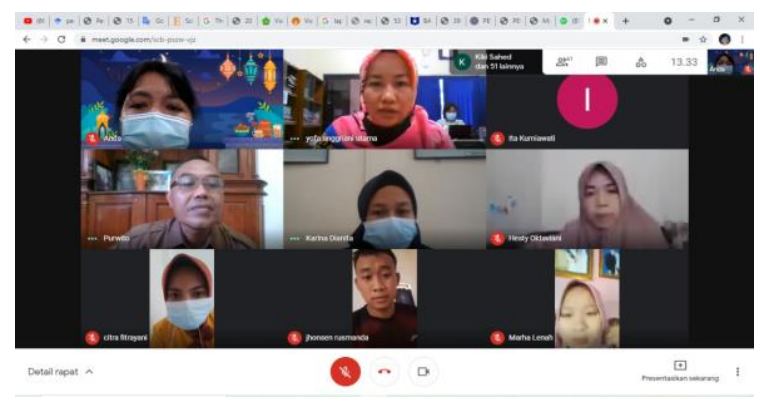




\section{Gambar 1 Peserta Kegiatan Pengabdian Kepada Masyarakat}

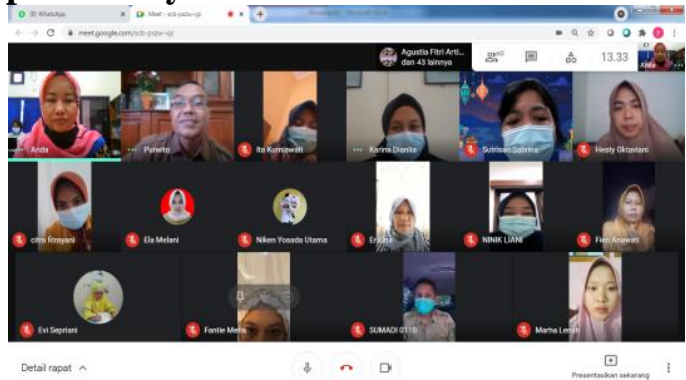

Gambar 2 Peserta Kegiatan Pengabdian Kepada Masyarakat

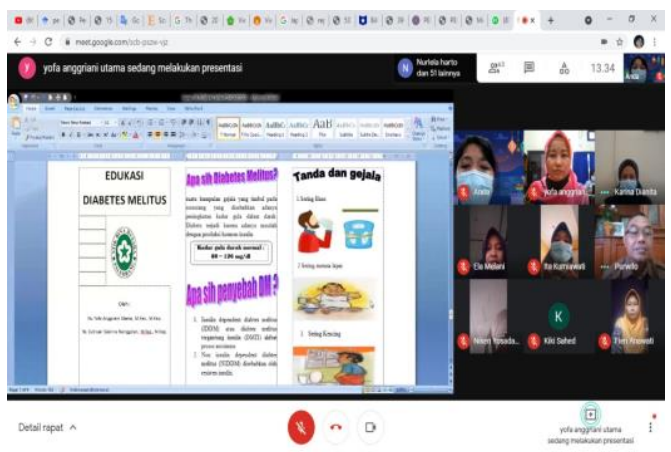

Gambar 3. Penyampaian Materi tentang edukasi diabetes melitus

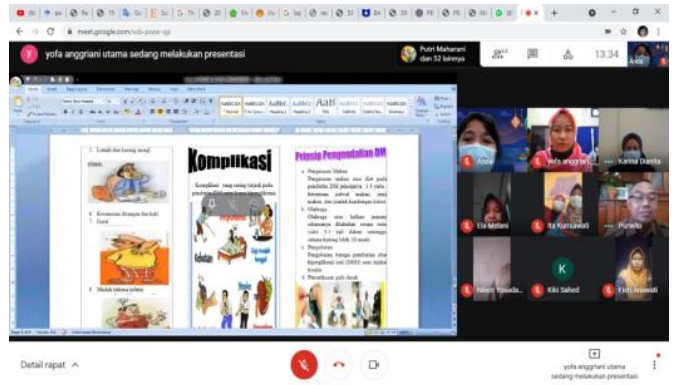

Gambar 4. Penyampaian Materi tentang edukasi diabetes melitus

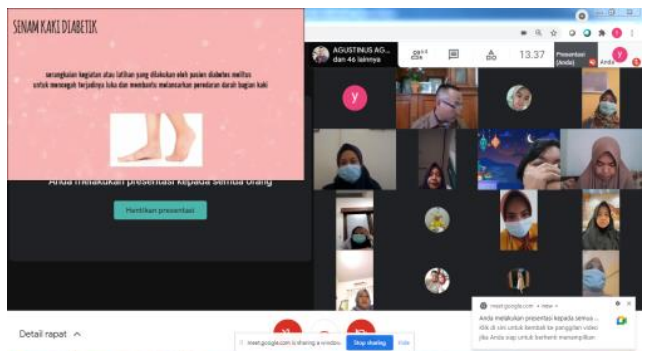

Gambar 5 Penyampaian materi 2 Senam kaki diabetik

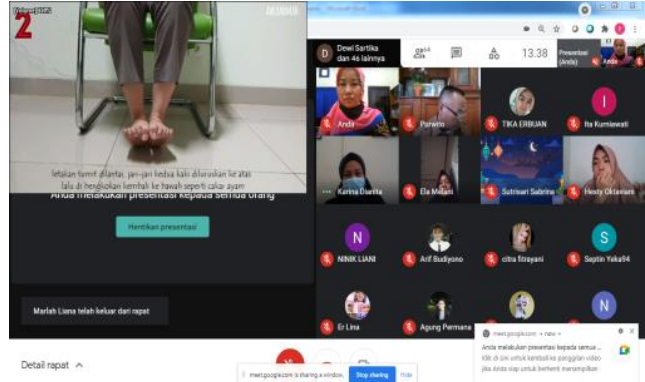

Gambar 6 Penyampaian materi 2 Senam kaki diabetik

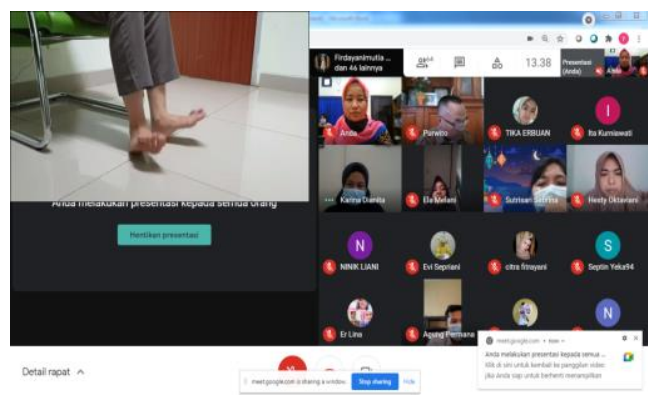

Gambar 7 Penyampaian materi 2 Senam kaki diabetik

\section{PEMBAHASAN}

Peserta pengabdian kepada masyarakat berbasis virtual sebanyak 60 orang peserta. Hasil evaluasi pelaksanaan pengabdian kepada masyarakat berbasis virtual didapatkan bahwa pengetahuan sebelum diberikan edukasi sebanyak 45 orang $(75 \%)$ pasien diabetes mellitus memiliki pengetahuan yang kurang baik tentang edukasi diabetes melitus dan senam kaki diabetik. Setelah diberikan edukasi terjadi peningkatan pengetahuan sebanyak 50 orang $(83 \%)$ peserta pengabdian masyarakat memiliki pengetahuan baik tentang edukasi diabetes melitus dan senam kaki diabetik.

Pengetahuan penderita diabetes mellitus di Surabaya terhadap perawatan kaki menunjukkan peningkatan nilai reratapost test menjadi 70 dari nilai rerata pada pre test 49 terhadap 30 peserta diabetes mellitus. Sementara itu, didapatkan 18 orang memiliki skor ABI dengan interpretasi borderline perfusion $(0,6-0,8)$ dan sisanya berada dalam rentang normal. Sedangkan setelah dilakukan latihan jasmani berupa senam kaki didapatkan 6 orang masih memiliki skor ABI rentang 0,60,8 dengan interpretasi borderline perfusion dan 24 orang berada dalam rentang normal 
dengan skor ABI 0,9-1,3.

Pengabdian kepada masyarakat yang dilakukan oleh Suhatridjas et al. (2020) didapatkan hasil evaluasi tingkat pengetahuan tentang komplikasi diabetes mellitus, yang mana pesertanya dapat menjawab terkait pengetahuan yang ditanyakan penyaji dan peserta menyatakanakan mengaplikasikan terkait perilaku dan keadaan fisik penderita berjalan dengan baik dibantu kader. Metode sosialisasi dengan penyuluhan memberikan pengaruh bermakna terhadap tingkat pengetahuan dan dengan pengetahuan tentang DM, yang dimiliki dapat diterapkan dalam kehidupan sehari-hari.

Hal yang sama juga diungkapkan olehSya'diyah et al. (2020), bahwa dengan adanya peningkatan pengetahuan tentang diabetes mellitus yang merupakan penambahan informasi dan wawasan tentang kesehatan serta memberikan gambaran yang jelas bagi lansia untuk pencegahan dan penatalaksanaannya. Begitu besar dampak dan komplikasi dari diabetes mellitus seperti komplikasi akut (hipoglikemi) dan komplikasi kronis (gangrene, retinopati, nefropati, neuropati, dll) sehingga perlu pencegahan dan penatalaksanaan lebih lanjut untuk tidak terjadi dampak yang lebih fatal.

Peningkatan pengetahuan masyarakat terutama pada penderita diabetes mellitus dapat dilakukan dengan memberikan infomasi dengan metode penyuluhan, sebelum dilaksanakn kegiatan penyuluhan dilakukan pre tes hasil yang didapatkan menunjukkan sebagian besar warga $(80 \%)$ belum memahami dan mengerti tentang pemeriksaan diabetes melitus.

\section{KESIMPULAN}

Berdasarkan hasil pelaksanaan kegiatan pengabdian kepada masyarakat berbasis virtual yang telah terlaksanakan dengan baik sesuai dengan rencana dan mendapat respon yang baik dari masyarakat RT 08 Kelurahan 22 Ilir Palembang dalam upayapengendaliankomplikasi diabetes mellitus.

Masyarakat menyadari akan pentingnya pengetahuan mengenai diabetes mellitus guna mencegah terjadinya komplikasi yang dapat terjadi pada penderita diabetes melitus dimasa pandemik covid 19 ini. Peran perawat dan kader posbindu saat ini sangatlah berperan dalam upayapengendaliankomplikasi,karena perawat dan kader posbindu dapat berperan sebagai edukator dimasyarakat dalam memberikan edukasi pada penderita diabetes mellitus. Hasil dari kegiatan pengabdian kepada masyarakat ini diharapkan dapat meningkatkan pengetahuannya tentang komplikasi diabetes mellitus, prinsip pengendalian makan pad apenderita diabetes mellitus, manfaat senam kaki diabetik, cara untuk perawatan kaki, dan tahap senam kaki diabetik.

\section{UCAPAN TERIMA KASIH}

1. Ketua STIK Bina Husada

2. Ketua PPM dan UPT STIK Bina Husada

3. Ketua RT 08 Kelurahan 22 Ilir Palembang

\section{REFERENSI}

Badan Penelitian dan Pengembangan Kesehatan. (2019). Laporan Provinsi Sumatera Selatan Riskesdas 2018. 9, 1-7.

[1]Desnita, R., Andika, M., Efendi, Z., \& Sugiharto. (2020). Pemberdayaan Pasien Dan Keluarga Dalam Manajemen Diet Diabetes Melitus Pada Masa Pandemi Covid-19 Di Kota Padang. Jurnal Implementasi Pengabdian Masyarakat Kesehatan (JIPMK), 2(2), 52-57.

[2]International Diabetes Federation, IDF Diabetes Atlas, 8th edition. (2017). Eighth edition 2017. In IDF Diabetes Atlas, 8th edition.

[3]Lita Puspita, M. Deni Indrawan, Murni Oktania, Eka Trismaiyana, Eka Yudha Chrisanto, Rilyani, R. ellya. (2020). Penyuluhan Pemeriksaan Diabetes Melitus Di Gang Mawar Kemiling ,Bandar lampung. 3, 382-387.

[4]Matos, M., Mendes, R., Silva, A. B., \& Sousa, N. (2018). Physical activity and exercise on diabetic foot related outcomes: 
A systematic review. Diabetes Research and Clinical Practice, 139, 81-90. https://doi.org/10.1016/j.diabres.2018.02.0 20

[5]Suhatridjas, Rizka, Tantrian, L., \& Afifah, I. (2020). Sosialisasi dan Deteksi Dini Diabetes Mellitus Sebagai Upaya Pencegahan Komplikasi. 2507(February), $1-9$.

[6]Sutarti, T., Abdul, M., Anwar, M., Siyoto, S., \& Saputra, M. H. (2018). The influence of diabetic foot gymnastic to body balance in elderly diabetes mellitus patients in gatoel mojokerto hospital diabetic club. Indian Journal of Public Health Research and Development, 9(12), 1334-1338. https://doi.org/10.5958/09765506.2018.02038.7

[7]Sya'diyah, H., Widayanti, D. M., Kertapati, Y., Anggoro, S. D., Ismail, A., Atik, T., \& Gustayansyah, D. (2020). Penyuluhan Kesehatan Diabetes Melitus Penatalaksnaan Dan Aplikasi Senam Kaki Pada Lansia Di Wilayah Pesisir Surabaya. Jurnal Pengabdian Kesehatan, 3(1), 9-27. https://doi.org/10.31596/jpk.v3i1.64 